\title{
An approach to waterflood optimization: case study of the reservoir $\mathbf{X}$
}

\author{
Precious Ogbeiwi $^{1} \cdot$ Yetunde Aladeitan $^{1,2} \cdot$ Dickson Udebhulu $^{1,3}$
}

Received: 3 November 2016/ Accepted: 17 June 2017/Published online: 6 July 2017

(c) The Author(s) 2017. This article is an open access publication

\begin{abstract}
Over the years, waterflooding has been the most widely used secondary oil recovery method after the exhaustion of the primary depletion energy of the reservoir. Waterflooding schemes have to be planned such that at every point of the operation, net income from oil recovery exceeds operating expenditure of which produced water disposal cost is paramount. Hence, engineers are regularly plagued with challenges such as optimal completions zones for injectors and producers, optimal flood pattern to adopt and number/type of producers and injectors to use in waterflood field development so as to improve oil recovery, but reduce water production. The aim of this study is to optimize waterflooding from a case study model using reservoir simulation techniques. A simple optimization methodology involving the analysis of the effects of zones of production and injection, pattern of waterflood selected and number/type of producers and injectors on cumulative recovery from a waterflooded reservoir was used. Results revealed that (1) pressure maintenance/increment is more effective when there is water injection into more zones of the reservoir, (2) for waterflood operations involving the
\end{abstract}

Precious Ogbeiwi

prejohn73@gmail.com

Yetunde Aladeitan

yetty76@yahoo.com

Dickson Udebhulu

udebhuludickson@gmail.com

1 Department of Petroleum Engineering, African University of Science and Technology, Abuja, FCT, Nigeria

2 Department of Chemical Engineering, University of Abuja, Abuja, FCT, Nigeria

3 Department of Chemical and Petroleum Engineering, Federal University, Abakaliki, Nigeria use of vertical injectors, higher water production was observed because water is expected to flow more conveniently in the upward direction due to gravity rather than laterally and (3) with horizontal injectors, higher cumulative production was achieved especially for cases where water is injected into the same zones from which oil is produced.

Keywords Waterflooding - Optimization - Reservoir · Simulation - Oil recovery $\cdot$ Performance

\begin{tabular}{ll}
\multicolumn{2}{l}{ List of symbols } \\
$A$ & Area \\
$h$ & Thickness \\
$\varphi$ & Porosity \\
$k$ & Permeability \\
$\mathrm{mD}$ & Millidarcy \\
$B_{\mathrm{O}}$ & Oil formation volume factor \\
$S_{\mathrm{W}}$ & Water saturation \\
FOPT & Field cumulative/total oil production \\
FOPR & Field oil production rate \\
FWCT & Field water-cut \\
FPR & Field pressure
\end{tabular}

\section{Introduction}

It has become increasingly necessary to produce oil and gas fields more economically and efficiently as a result of the ever-increasing demand for petroleum worldwide. Since a significant number of prominent oil fields are mature fields and the number of new discoveries per year is decreasing, it is become more imperative to use secondary oil recovery processes (Nwaozo 2006).

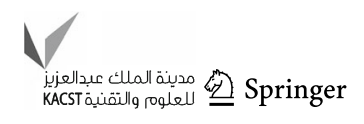


Over the years, waterflooding has been most widely used secondary oil recovery method after the exhaustion of the primary depletion energy of the reservoir (Craft and Hawkins 1991). Waterflooding basically involves pumping water through an injection well into the reservoir. The water then forces itself through the pore spaces and sweeps the oil toward another set of wells known as producers. As a result, there is an increment in the total oil production from the reservoir. However, the percentage of water in the produced fluids steadily increases. On the average, this process can lead to the recovery of about one-third of the original oil in place (OOIP), leaving behind about twothirds (Meshioye et al. 2010). According to Craig (1971), the popularity of water injection is mainly due to its availability, mobility, displacement efficiency and ease of injection. At some point during waterflooding operations, it becomes uneconomical to continue these operations because the cost of removing and disposing of water exceeds the net income generated from the oil production (Lake et al. 1992).

Due to the ever-increasing necessity of producing oil reservoirs optimally by improving oil recovery, minimizing water production and better maintenance of reservoir pressure, engineers are plagued with challenges such as optimal completions zones for injectors and producers, optimal flood pattern to adopt and number/type of producers and injectors to use in oil field waterflood development. These problems are commonly encountered in waterflood operations.

Some waterflood optimization problems are undertaken by some researchers.

Meshioye et al. (2010) presented a methodology in which waterflooding is been controlled by smart injector well technology to help optimize or increase the net present value of the field. The optimization procedure was carried out on three different case studies of commingled reservoir having different layer characteristics. A setup optimization procedure was applied, where rate allocation method was used at each zone of the smart injector well. The major drawback of their work was that the layers were not discretized to incorporate the effect of vertical communication and gravity within the layers.

Other researches such as those conducted by Spath and McCants (1997), Alhuthali et al. (2006) and Ogali (2011) aimed at predicting and optimization of waterflood performance by employing a combination of geostatistical and dynamic reservoir simulation techniques.

Spath and McCants (1997) studied waterflood optimization using a combined geostatistical 3D streamline approach. They used a combination of stochastic reservoir description techniques and streamline simulation to optimize volumetric sweep efficiency in a mature West Texas waterflood and used an IMPES, finite-difference scheme to validate the results obtained. Geostatistical techniques including kriging and co-kriging were used to generate realizations of property distributions used, and performance predictions were made for the placement of new infill wells (vertical and horizontal), as well as for pattern modification by selectively shutting in existing injectors. Their results showed that the combination of multiple realization property distribution with an efficient streamlined model is a much better alternative to the traditional, finite-difference approach. However, Bohling (2005) suggest the sequential Gaussian is a better tool for generating property distributions than kriging. This is because it provides a means for generating multiple equiprobable realizations of the property in question, rather than simply estimating the mean.

Alhuthali et al. (2006) carried out a robust optimization which aimed at maximizing the sweep efficiency of the reservoir using multiple geological scenarios based on equalizing the breakthrough time of the waterfront at all producers. They validated the approach using $2 \mathrm{D}$ synthetic and 3D field models. Their results showed that the approach was computationally and practically efficient in optimizing the injection/production rates in a waterflooding project. However, their approach did not consider a stochastic approach to waterflood optimization on multiple realizations and quantification of uncertainty associated with the optimization results.

Ogali (2011) conducted a research which focused on the optimization of waterflood using streamline simulation. The streamline-based simulation workflow used for computing well allocation factors (WAFs) and injection efficiencies was proposed by Thiele and Batycky (2006). These efficiencies were used to optimize oil recovery by effectively reallocating water available for injection. The proposed methodology was validated with a case study which showed that reallocating available injection water to more efficient injection wells in a five-spot pattern waterflood leads to optimization of oil production. The results showed that $\mathrm{kV} / \mathrm{kH}$ ratio, heterogeneity and zones of injection all play a significant role in the performance of waterflooding. However, his study involved analysis of the impact of several factors on waterflooding and waterflood optimization in the five-spot pattern only and other waterflood patterns were not considered. Optimization analysis would be more appropriate if the results from the five-spot pattern were compared with other waterflood patterns.

This paper focuses on the use of geostatistical methods to map reservoir properties and combining these methods with numerical reservoir simulation techniques to optimize oil recovery from the reservoir by carrying out comparative analysis on several factors that influence production and waterflood performance in a case study. Multiple 
equiprobable realizations of reservoir properties models were generated using co-sequential Gaussian simulation (COSGSIM). They were ranked so as to reduce disparities between the simulated and actual reservoir properties. These models were then employed in reservoir simulation and waterflood performance analysis. The effects of some important parameters on waterflood performance were also analyzed. These parameters include zones of injection and production (ZoIP), waterflood pattern (PoWF) and number/types of injectors and producers (NToW).

\section{Methodology}

This research involved the evaluation of several waterflood optimization scenarios for a case study with data obtained from a field in the Gulf of Mexico, USA, arbitrarily named Reservoir X. The scope of this research does not include creating an actual development and production strategy that can be implemented in this field of interest. Rather, it involves using reservoir simulation techniques to optimize oil recovery from the reservoir by carrying out comparative analysis on several factors that influence production and waterflood performance in any given reservoir, such as zones of injection and production (ZoIP), waterflood pattern (PoWF) and number/types of injectors and producers (NToW). Hence, a test dataset provided by the simulator was adjusted to the various scenarios that were studied.

The optimization procedure involved analyzing the effect of zones of injection and production, pattern of waterflood as well as the number/type of producers and injectors on cumulative oil recovery. This was carried out using reservoir simulation techniques. Tools used in this research included: Stanford Geostatistical Modeling Software (SGEMS) and Coates Engineering Sensor 6K (Coates 2013). SGEMS was used to populate the reservoir model with petrophysical properties, such as net-to-gross ratio, shale volume, porosity and permeability. Sensor $6 \mathrm{~K}$ was used in carrying out simulations for the different scenarios analyzed. Figure 1 presents a flow chart for the methodology.

\section{Reservoir description}

This research was conducted using data obtained from Lach (2010). The reservoir $X$ is located in the Gulf of Mexico. The reservoir is made up of a series of turbidite sands of the Miocene to Pliocene age which is deposited within a mini-basin. It was a good candidate for secondary recovery because the reservoirs have limited aquifer influx, was very over-pressured and compacting and was undersaturated. The reservoirs also have good structure relief, good connectivity and directional permeabilities. Its sands are generally characterized as sheet sands and channelized deposits, but massive fine- and very fine-grained sands are also observed. The sheets have excellent lateral pressure communication, and shales at the internal zones do not necessarily divide the reservoir into compartments as seen from production and pressure history.

Seawater injection commenced in 1999 when reservoir pressure was about 6800 psia, approximately 4500 psi below the original 11,305 psia. Some of the waterflood objectives are to maintain/stabilize pressure to prevent the sands from producing below their bubble points and to minimize well completion failures. Its original oil in place is estimated at 5.6 MMSTB. Table 1 shows the average properties of the reservoir $\mathrm{X}$.

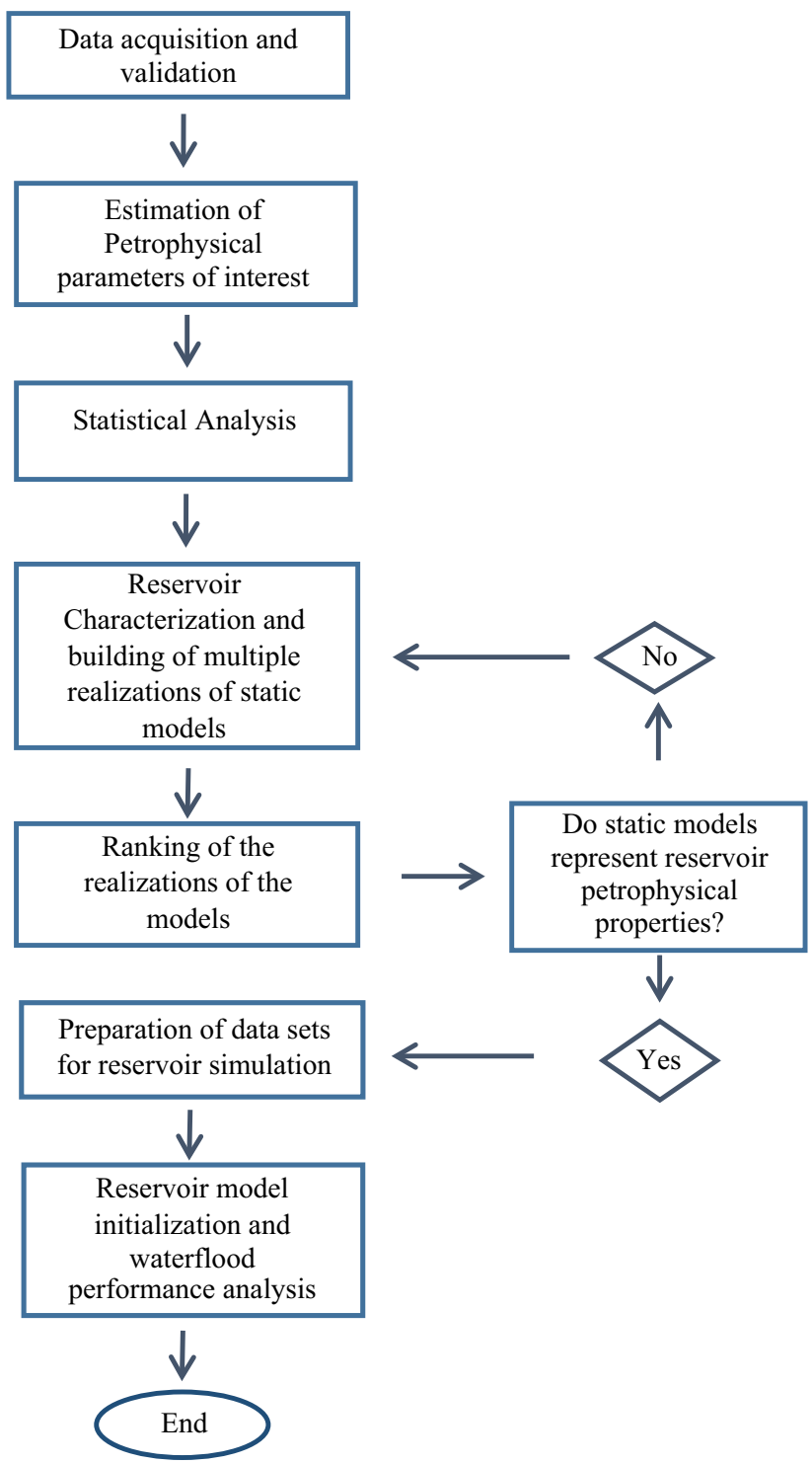

Fig. 1 Flowchart for methodology 
Table 1 Average properties of the reservoir X

\begin{tabular}{ll}
\hline Property & Value \\
\hline Area (Acre) & 3.59 \\
Average porosity, $\varnothing(\%)$ & 28 \\
Average water saturation, $S_{\mathrm{w}}(\%)$ & 0.22 \\
Net/gross sand & 0.9 \\
Average permeability, $(\mathrm{mD})$ & 125 \\
Reservoir thickness, $(\mathrm{ft})$ & 99 \\
Datum depth $(\mathrm{ft})$ & 16,726 \\
Initial reservoir pressure at datum, $P_{\mathrm{R}}(\mathrm{psia})$ & 11,305 \\
Bubble point pressure $(\mathrm{psia})$ & 6306 \\
Oil viscosity, $\mu(\mathrm{cP})$ & 0.782 \\
Oil initial $\mathrm{FVF}(\mathrm{rb} / \mathrm{stb})$ & 1.39 \\
Anisotropy $\left(\mathrm{k}_{\mathrm{V}} / \mathrm{k}_{\mathrm{H}}\right)$ & 0.6 \\
\hline
\end{tabular}

\section{Estimation of petrophysical parameters of interest}

The petrophysical parameters of interest were estimated from well logs using well-established methods which have been known to work perfectly in the Gulf of Mexico area. A typical $\log$ for a well in the reservoir $\mathrm{X}$ used in this estimation is shown in Fig. 2. The procedure used for the estimation of these properties is described in the following sections.

\section{Porosity}

In this study, the porosity of the reservoir in this report is estimated by using the density log. The porosity of the reservoir was calculated using the equation shown below:

$\emptyset_{\mathrm{TD}}=\frac{\left(\rho_{\mathrm{ma}}-\rho_{\mathrm{b}}\right)}{\left(\rho_{\mathrm{ma}}-\rho_{\mathrm{f}}\right)}$

where $\emptyset_{\mathrm{TD}}=\emptyset_{\mathrm{T}}=$ total porosity estimated from density $\log ; \rho_{\text {ma }}=$ matrix (or grain) density; $\rho_{\mathrm{b}}=$ bulk density; and $\rho_{\mathrm{f}}=$ density of the fluid.

\section{Net pay thickness (net/gross)}

This is the ratio of the sum of the thicknesses of the net pay zone to the total thickness or depth of the well (Awejori 2010). This is usually obtained by measuring from the top of the sand to the bottom of the sand. The net thickness is composed of the aggregation of delineated net pay zones established using some petrophysical logs. From this point, the ratio of the net to gross reservoir thickness can then be estimated for each well.

\section{Shale volume $\left(V_{\text {sh }}\right)$}

The volume of shale ( $V$ sh) in these sand bodies can be estimated by means of the equations given below. Firstly, the gamma ray index $I_{\mathrm{GR}}$ is calculated from the gamma ray $\log$ using the formula presented below:

$I_{\mathrm{GR}}=\frac{\left(\mathrm{GR}_{\log }-\mathrm{GR}_{\min }\right)}{\left(\mathrm{GR}_{\max }-\mathrm{GR}_{\min }\right)}$

where $I_{\mathrm{GR}}$ is the gamma ray index, GR $\mathrm{log}_{\mathrm{g}}$ is the gamma ray $\log$ reading of the formation, $\mathrm{GR}_{\min }$ is the gamma ray for a complete sand matrix zone (clay free zone) and $\mathrm{GR}_{\max }$ is the gamma ray for a complete shale zone (100\% clay zone).

The shale volume is then determined using the gamma ray index obtained above, and below using the Larionov equation for calculating volume of shale for unconsolidated tertiary sandstones (Tiab and Donaldson 2004).

$V_{\mathrm{sh}}=0.083 *\left[2^{\left(3.7 \times I_{\mathrm{GR}}\right)}-1\right]$

Shale volume $V_{\text {sh }}$ is used in the calculation of effective porosity, $\emptyset_{\mathrm{e}}$.

\section{Permeability}

In this study, the Timur equation which is an experimental relation between permeability, effective porosity and water saturation was adopted to estimate the permeability. The equation is given as:

$K=8581 \frac{\emptyset_{\mathrm{e}}^{4.4}}{S_{\mathrm{wi}}^{2}}$

where $K=$ permeability, $\emptyset_{\mathrm{e}}=$ effective porosity and $S_{\mathrm{wi}}=$ irreducible water saturation.

The effective porosity $\emptyset_{\mathrm{e}}$ is estimated as: $\emptyset_{\mathrm{e}}=\emptyset_{\mathrm{TD}}-$ $\left(\emptyset_{\mathrm{TD}} \times V_{\mathrm{sh}}\right)$.

\section{Reservoir characterization and static reservoir modeling}

The Stanford Geostatistical Modeling Software (SGEMS) is an open-source computer package for solving problems involving spatially related variables (Remy et al. 2009). In this research, it was used to spatially distribute petrophysical properties across the reservoir model. The properties evaluated include: total porosity, permeability and net-to-gross ratio. For each property, anisotropic variograms were used to adequately capture the spatial correlation between data points.

\section{Statistical analysis}

Porosity

From the histogram for porosity shown in Fig. 3, a unimodal porosity distribution is observed with the minimum 
and maximum porosity values of $0.07(6.96 \%)$ and 0.385 (38.5\%), respectively. The most occurring porosity values are between 0.25 and 0.26 . The mean porosity value is 0.24 $(24.3 \%)$, and the standard deviation is $0.06(6.5 \%)$.

To aid in the generation of equiprobable realizations of porosity across the model, variogram analysis was conducted on the dataset in which the Gaussian model was used to fit the dataset by visual inspection. The variogram direction captured the spatial variation in the porosity data points.

\section{Permeability}

Figure 4 shows a histogram of the permeability data. A unimodal distribution was observed with the data range of
10-100 md (logperm values of 1-2) as the most likely. The average permeability is $1.92(83.1 \mathrm{md})$, and the standard deviation is $1.87(73.79 \mathrm{md})$. The range of log perm values was between $-4.05(0.0001 \mathrm{md})$ and $3.43(2700 \mathrm{md})$. Variograms were then built to capture the spatial variation in permeability between data points which was then used in the building of equiprobable realizations of the permeability distribution across the model using sequential Gaussian simulation (SGSIM).

\section{Net to gross}

Figure 5 shows the histogram of the net-to-gross ratio across the model. It is observed that the NTG values peaked at $97.4 \%$ with the lowest value occurring at $55.4 \%$.

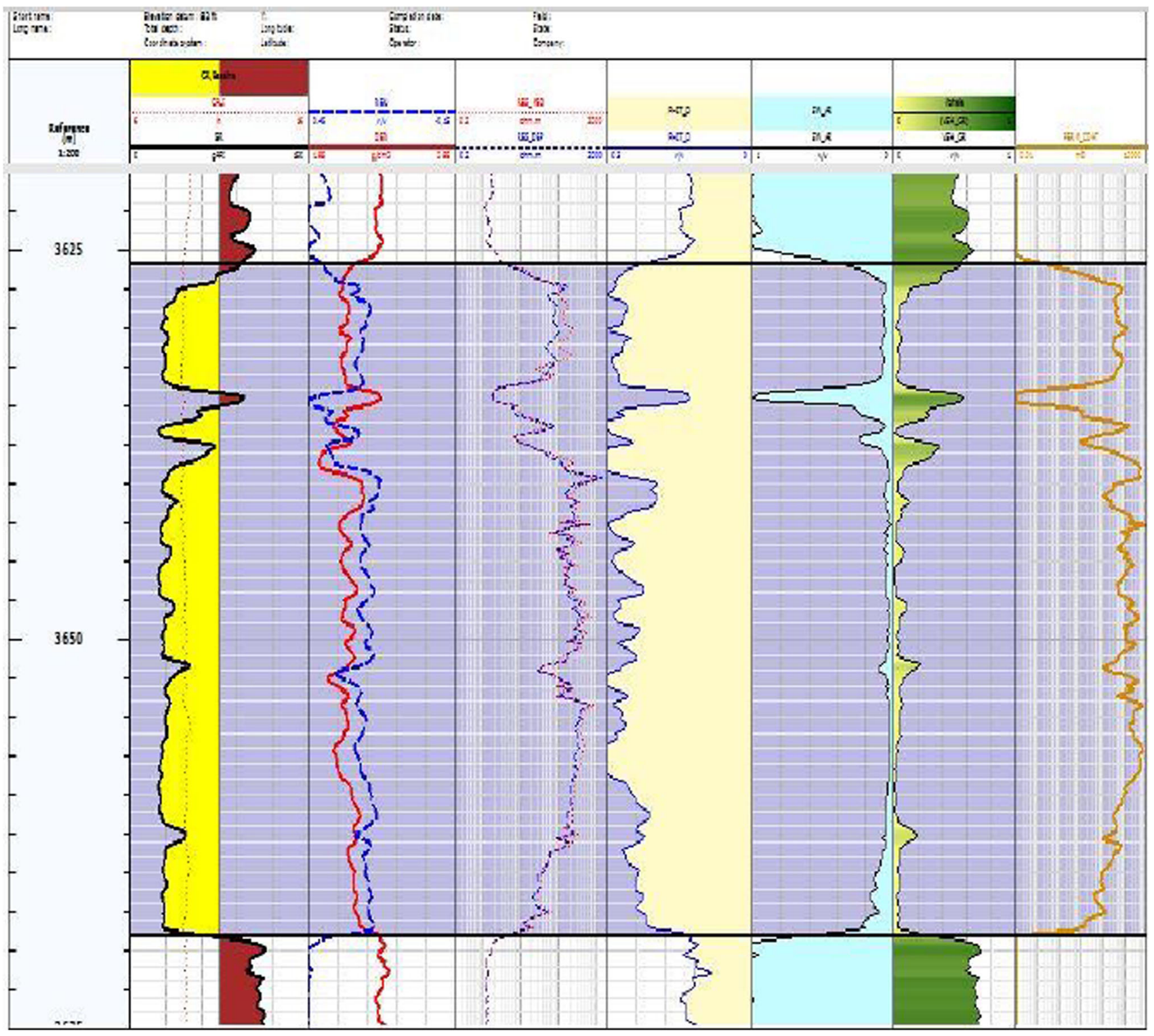

Fig. 2 Typical $\operatorname{logs}$ for a well in the reservoir X (Awejori 2010) 

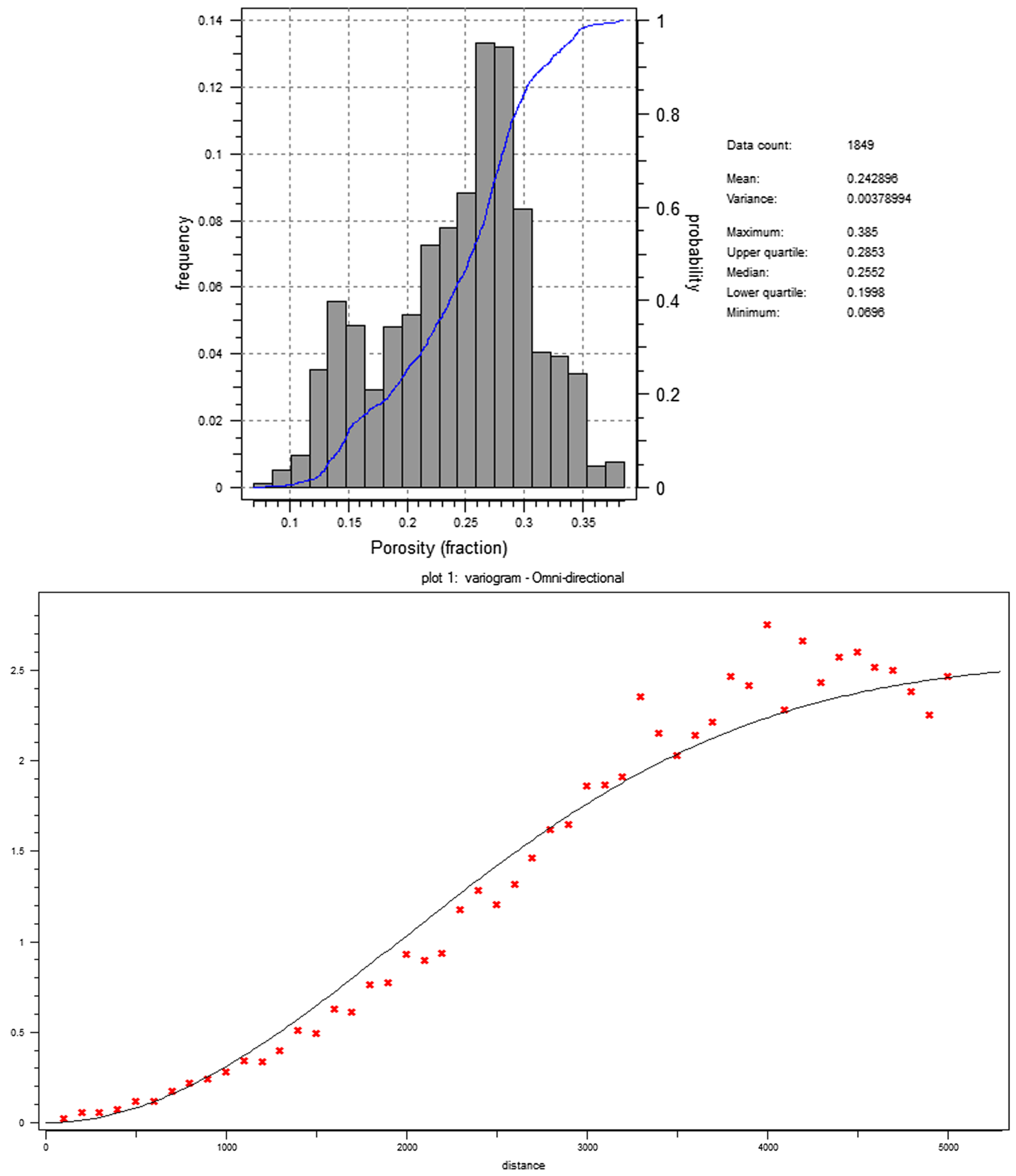

Fig. 3 Histogram and variogram for porosity across the model

From the histogram plot, a unimodal distribution was observed. It was also observed that the most occurring or likely NTG value is around 55\%. The mean value is $76.03 \%$ while a standard deviation of $19.6 \%$ was observed.
To model the spatial correlation between the data points, an anisotropic variogram was built. This was used in generation of realizations of net-to-gross distributions across the reservoir model. 

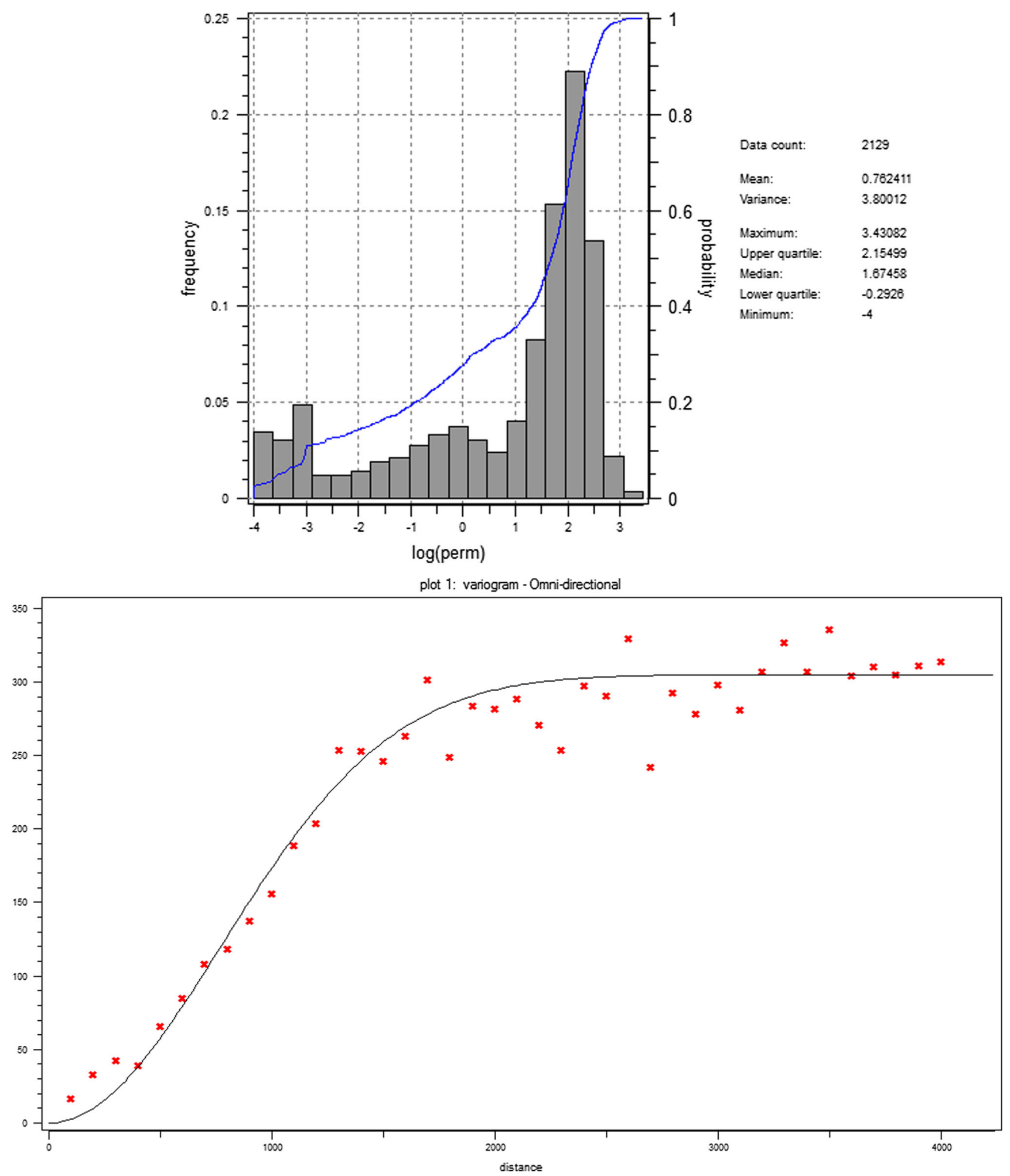

Fig. 4 Permeability histogram and variogram for the reservoir X

\section{Geostatistical modeling of reservoir properties}

To statistically estimate the reservoir petrophysical properties over the entire volume of the reservoir $\mathrm{X}$ model, geostatistical simulation was used. Stochastic simulation was used instead of kriging so as to make it possible for the generation of multiple equiprobable realizations of the reservoir which allows for assessment 

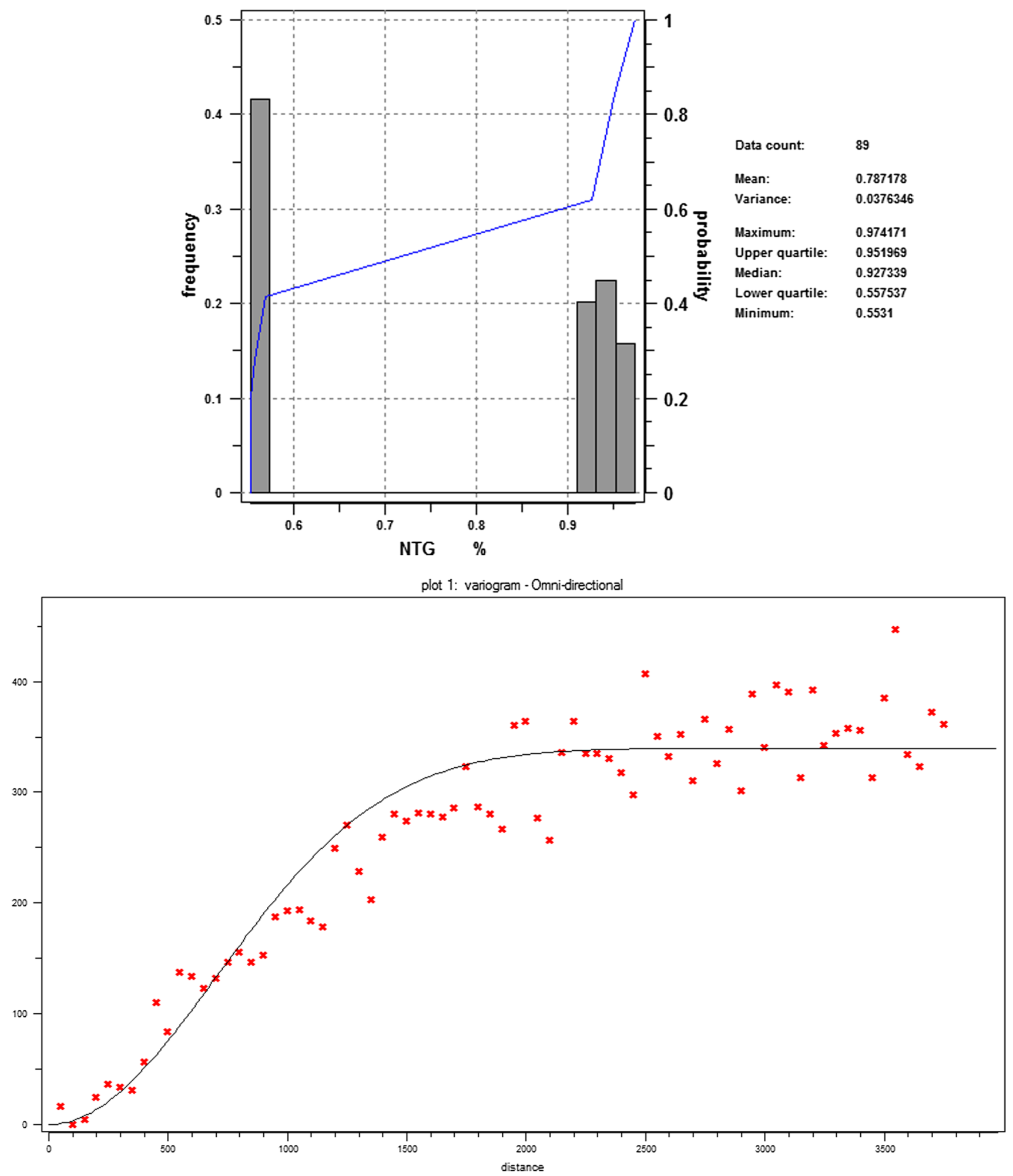

Fig. 5 Histogram and variogram for net to gross across the model 
Table 2 Summary of grid data used in static modeling

Cell dimensions (in feet)

Length

400

Width

Thickness

Number of cells in the $X$-direction

Number of cells in the $Y$-direction

Number of cells in the $Z$-direction

Total number of cells

of uncertainty. Table 2 shows a summary of the grid data used.

\section{Petrophysical modeling}

Co-sequential Gaussian simulation (COSGSIM) was used to generate five realizations of each reservoir properties accessed. Sequential Gaussian simulation (SGSIM) is a more efficient tool than kriging (Bohling 2005) while kriging gives an estimate of both the mean and standard deviation of the variable at each grid node, meaning that we can represent the variable at each grid node as a random variable following a normal (Gaussian) distribution. Rather than choosing the mean as the estimate at each node, SGSIM chooses a random deviation from this normal distribution, selected according to a uniform random number representing the probability level. The parameters obtained from the variogram analysis were used in this exercise. For each property, maximum conditioning data of 12 were used with a seed value of 14,071,789. These properties are porosity and shale volume, permeability and porosity, and finally net to gross and porosity. Figures 6, 7 and 8 show the simulation maps for permeability, porosity and net-to-gross ratio, respectively.

\section{Ranking of static reservoir models built}

Five static equiprobable descriptions of each reservoir property were generated using SGEMS. Table 3 shows the results of the statistical means of reservoir petrophysical properties obtained from the realizations maps generated for porosity, absolute permeability and net to gross while comparing them with the statistical means before static simulation, i.e., those from the raw data.

Fig. 6 Simulation map showing permeability distribution across the reservoir $\mathrm{X}$ model
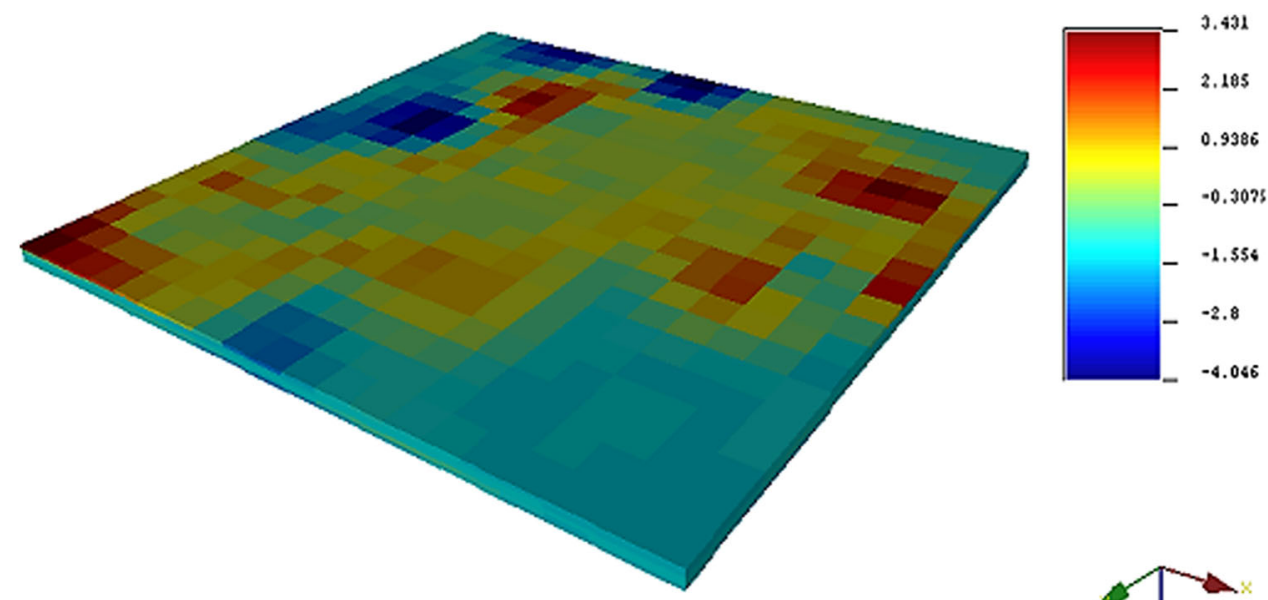

Fig. 7 View of porosity distribution
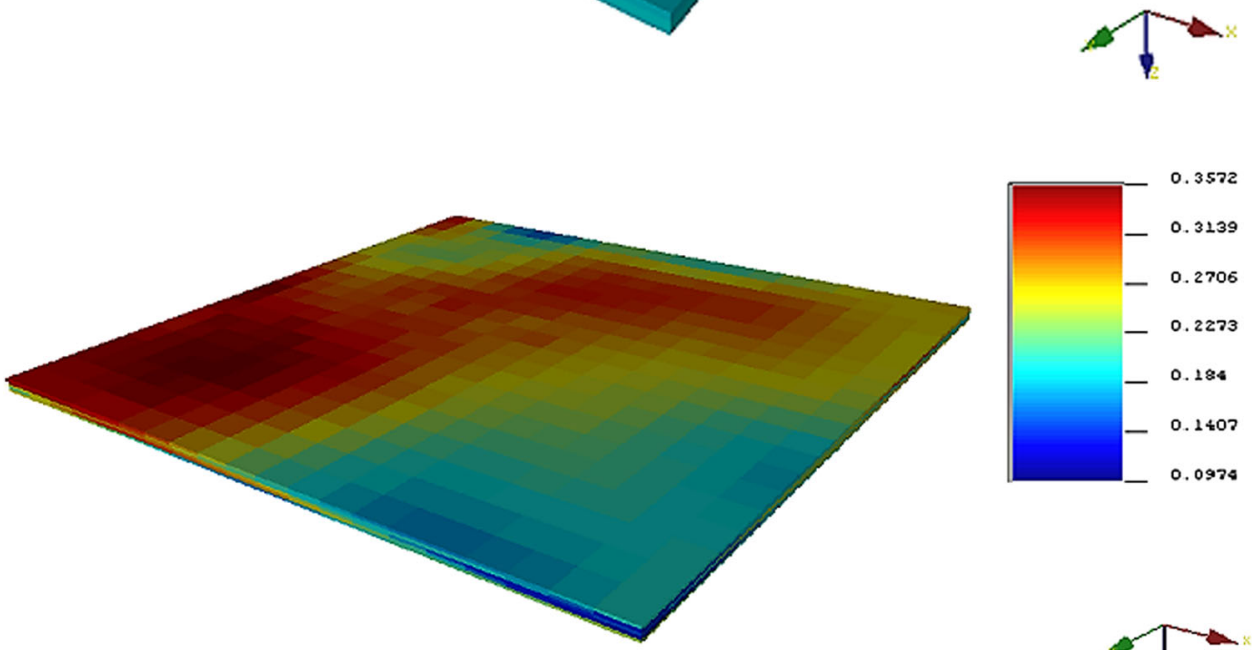
Fig. 8 Map of net-to-gross distribution across the model

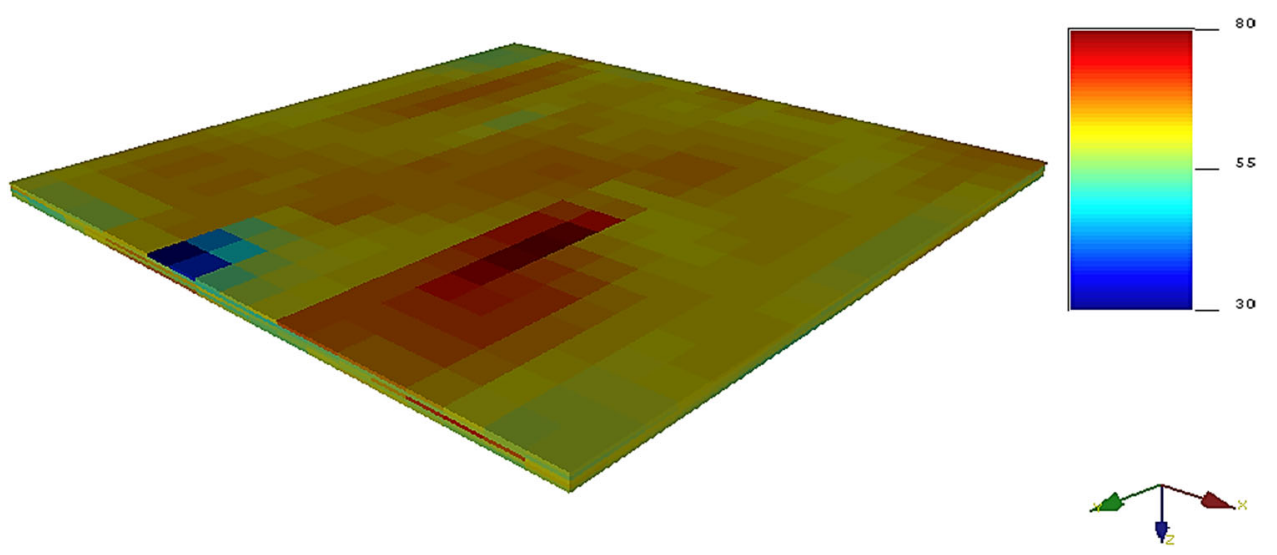

Table 3 Summary of the statistical means before and after building realizations

\begin{tabular}{|c|c|c|c|c|c|}
\hline \multirow{2}{*}{$\frac{\text { Property }}{\text { Porosity }}$} & \multicolumn{2}{|c|}{ Before COSGSIM } & \multicolumn{2}{|l|}{ After COSGSIM } & \multirow{2}{*}{$\frac{\text { Real. no }}{2}$} \\
\hline & Mean & 0.24 & Minimum mean & 0.15 & \\
\hline & & & Mean (for all realizations) & 0.19 & \\
\hline & & & Maximum mean & 0.24 & 3 \\
\hline \multirow[t]{3}{*}{ Permeability } & Mean & $1.92(83.1 \mathrm{mD})$ & Minimum mean & $1.86(65.3 \mathrm{mD})$ & 5 \\
\hline & & & Mean (for all realizations) & $1.82(66.5 \mathrm{mD})$ & \\
\hline & & & Maximum mean & $1.889(76.9 \mathrm{mD})$ & 3 \\
\hline \multirow[t]{3}{*}{ Net to gross } & Mean & $76.03 \%$ & Minimum mean & $68.06 \%$ & 4 \\
\hline & & & Mean (for all realizations) & $69.11 \%$ & \\
\hline & & & Maximum mean & $71.05 \%$ & 3 \\
\hline
\end{tabular}

Generally, the mean values after simulation of the petrophysical properties are slightly smaller than those of the raw data. This observation may be as a result of the variogram parameters employed for each property. Also, the variations in the maximum and minimum average values (as shown in Table 3) suggest the extremely high and low cases of what the reservoir static model could be are well represented. As a result, the third realizations of the models of porosity, permeability and net to gross were used in used in the waterflood simulation studies.

This shows that building of multiple equiprobable realizations of reservoir properties and ranking them are an efficient approach to reservoir characterization. This approach reduces uncertainties associated with reservoir properties estimation.

\section{Reservoir simulation model initialization}

The reservoir X model is an undersaturated reservoir with an initial average reservoir pressure of 11,305 psia. The oil initially in place (OIIP) after initialization is put at 5.6 MMSTB. The properties of the reservoir used in the model initialization are given in Table 1 . The reservoir model is a five-layered model with 1410 active grid cells. The effects of gravity segregation as well as fluid and rock compressibilities were included in the simulation runs of the model. The start time for the simulation is June 1, 1996.

\section{Waterflooding of the reservoir $\mathbf{X}$}

\section{Reservoir development plan}

The production scheme used for this reservoir model involved two stages. Firstly, the development of the field began in June 1996, with just one producer with an oil flowrate of $1000 \mathrm{STB} /$ day for the five-spot pattern scenario and two producers at oil rates of $500 \mathrm{~S} \mathrm{~TB} /$ day each for the scenarios of direct line and staggered line scenarios. Upon production, it was decided that waterflooding should be commenced after three years of production and it was carried out for ten years.

Waterflooding was carried out to increase and/or maintain reservoir pressure above bubble point (6306 psia) and to increase the oil-producing rate of the field. Waterflooding started in June 1999 with four injectors for each of the scenarios, all injecting at a rate of 700 STB of water/day. The injectors were positioned such the waterflood pattern approximated the regular five-spot, direct line drive and staggered line patterns corresponding to their respective scenarios. Figure 9 shows the reservoir model and location of a producer at the end of primary production. 
Fig. 9 Case study map surface map showing the location of a producer

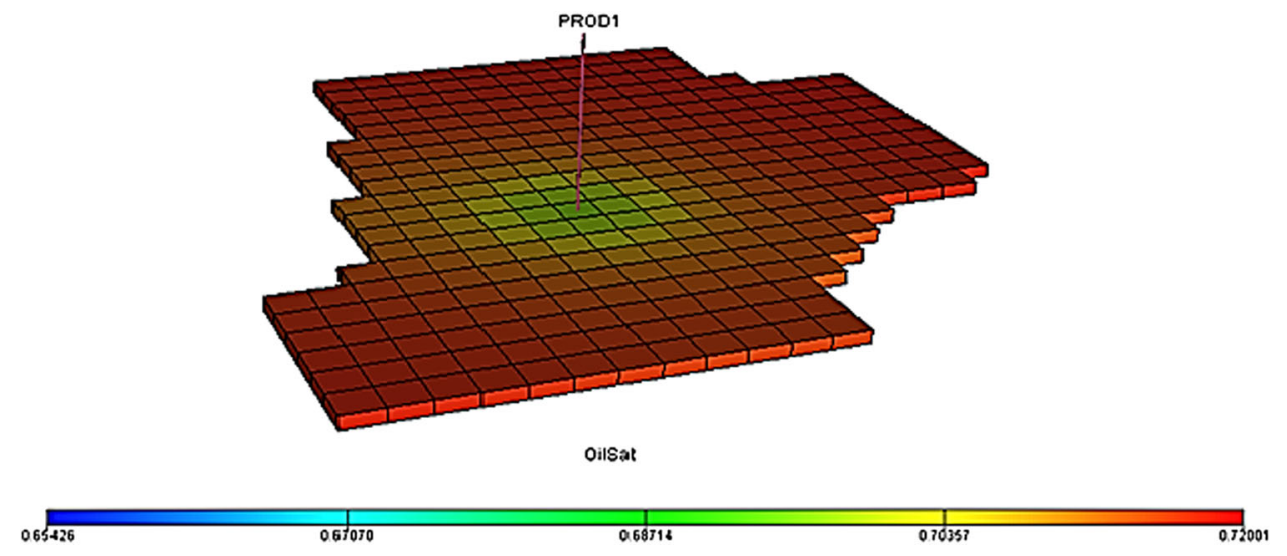

These rates were used throughout the period of simulation. The economic limit for producers consists of 50STB/day for production rate and a maximum water-cut of 0.95 . This production strategy was used for analysis of the effects of zones of injection/production (ZoIP), the pattern of waterflood (PoWF) and the number and type of injectors/producers (NToW) on waterflooding. As earlier stated, comparisons of waterflood performance were based on field average reservoir pressure (FPR), cumulative oil production (FOPT) and field water-cut (FWCT) for a period of thirteen years ( 3 years of primary depletion and 10 years of waterflooding).

\section{Waterflood optimization}

In defining a reservoir optimization problem, an objective function, optimization variables and their constraints should be specified (Asadollahi 2012). Objective functions for waterflood optimization include net pressure value (NPV), cumulative production or delay in water breakthrough/reduction in water-cut while controlling variables such as injection rate, oil production rate and/or bottom hole pressure of injectors and producers.

For this research, waterflood optimization aimed at increasing cumulative oil production while taking into consideration the zones of water injection and oil production, the pattern of waterflood and the number and type of injectors/producers, i.e.,

Cumulative oil production $=f$ (Zones of water injection $/$ oil production, waterflood pattern,

Number and type of injectors/producers)

\section{Methodology for analyzing the effects of zones of injection and production (ZoIP) on waterflood performance}

The simulation was carried out for 13-3 years of primary depletion and 10 years of waterflooding. In so doing, the effect of zones of injection as well as production on the reservoir performance was analyzed. The cases chosen are explained below:

- Case 1 (ZONES 4-5): This case involved waterflooding after three years of primary production. Production was carried out from two zones-layers 3 to 4 , and water was injected into the fourth and fifth zones of the reservoir-layers 4 to 5 .

- Case 2 (ZONE 4): For this scenario, production was carried out from two zones-layers 3 to 4 , and water was injected the zone close to the water-bearing zonelayer 4.

- Case 3 (AQUIFER): Here, two zones of the reservoir were completed-layers 3 to 4 , and water was injected in the water-bearing zone-zone 5.

An important reason for carrying out a study on the effect of the zones of production and injection was to ascertain the best zones for completing of the injectors and production so as to get optimal oil production and water injection. This was required for further analyses in this research. These scenarios were carried out adopting a regular five-spot pattern.

\section{Methodology for analyzing the effects of waterflood pattern (PoWF) on waterflood performance}

To select the optimal waterflood pattern for producing the reservoir X, it was necessary to analyze the performance of several waterflood patterns. The reservoir development involved two stages-primary production and waterflood. The first stage involved primary depletion of the reservoir using the reservoir's energy. After three years of production, oil production declined rapidly and it was decided to commence waterflooding. This marked the second stage of reservoir development, and it was carried out for 10 years.

All producers were completed in two zones-layers 3 to 4 , and water was injected in two zones only-layers 4 to 5 . This conclusion was reached based on results obtained from the ZoIP cases. The scenarios analyzed included the 
Fig. 10 Case study surface map showing the location of the producer and the injectors for the five-spot waterflood pattern
Fig. 11 Map showing the location of wells in the direct line drive waterflood pattern
Fig. 12 Map showing the location of wells in the staggered line drive waterflood pattern
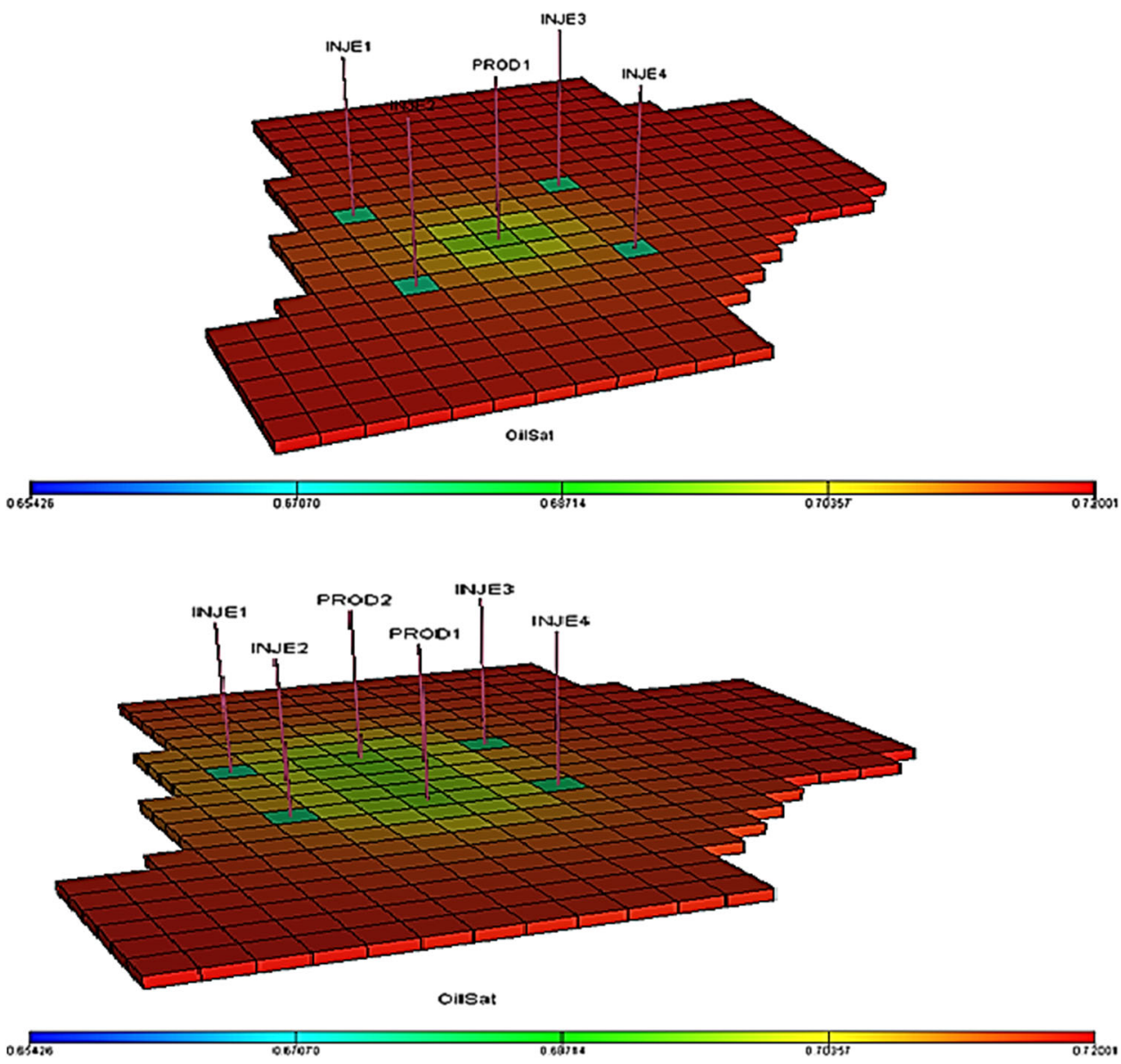

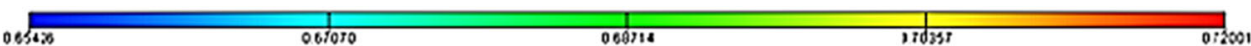

five-spot pattern (5_SPOT), the direct line drive pattern (LD) and the staggered line drive pattern (SLD). Figures 10 and 11 show schematics of the location of producer(s) and injectors in the five-spot, direct line drive and staggered line drive waterflood patterns, respectively (Fig. 12).

For the five-spot pattern scenario, the distance between all the injectors was constant. The four injectors formed a square with the production well in the center. For the direct line drive pattern, the lines of injection and production were directly opposite each other. For the staggered line drive pattern, the wells are in line similar to those in the direct line drive pattern with the same injection and production rate. However, the injectors and producers are no longer directly opposed to each other, but laterally displaced. 
Also, the injectors and producers for all the patterns of waterflood considered were constrained so that total injection rate for all the injectors was 2800 stb/day of water, and the total production rate from the producers was $1000 \mathrm{stb} /$ day. This was carried out so as to provide a basis for comparison.

\section{Methodology for analyzing the effect of number and type of injectors/producers (NToW)}

To effectively produce the reservoir $\mathrm{X}$, sensitization on the number and type of producers and injectors that will optimally drain the reservoir was carried out.

Based on results obtained from the study on the effect of pattern of waterflood, the direct line drive pattern was adopted and waterflooding commenced after three years of primary production and total simulation period was thirteen years. The use of vertical and horizontal wells was analyzed. For scenarios involving vertical wells, the producers were completed in two zones-layers 3 to 4 and water was injected in two zones only-layers 4 to 5 . While for scenarios involving horizontal wells, the producers were drilled in layer 4 while injectors were drilled in layer 4 . Scenarios analyzed include:

- Case 1 (VI_VP): This case involved the use of a total of six vertical wells-two producers and four injectors.

- Case 2 (HI_VP): For this scenario, all wells were horizontal wells. A total of four wells were employedtwo horizontal injectors and two vertical producers.

- Case 3 (VI_HP): Here, combinations of vertical and horizontal wells were employed. A total of five wellsfour vertical injectors and one horizontal producerwere drilled.

- Case 4 (HI_HP): In this scenario, all wells are horizontal wells. Three wells-two injectors and one producer-were drilled.

\section{Results and discussion}

The results obtained from the waterflooding of the reservoir $\mathrm{X}$ are presented in this chapter. The analysis of these results is discussed, and observations derived from the results are also included in this chapter.

\section{Waterflood optimization}

Effects of zones of production and injection on waterflood performance

In this section, the effect of zones of injection and production on the reservoir's primary depletion and waterflood performance was analyzed. This was carried out in order to ascertain the best zones for completing of the injectors and production so as to get optimal oil production and water injection. Results from this study were used for further analyses in this research. From results obtained, it was seen that injecting and producing from some zones were optimal compared to other zones. Hence, the zones of completion of injectors and producers play a vital role in waterflood performance. The pattern discussed is the regular five-spot pattern.

Effects of ZoIP on field cumulative oil production (FOPT)

Figure 13 shows a plot of cumulative oil production versus time of all the ZoIP cases analyzed (cases ZONES 4-5, ZONE 4 and AQUIFER) for the five-spot waterflood for a simulation period of thirteen years - three years of primary production and ten years of waterflood. It is observed that cumulative oil production for all cases increases with time within the case of production from zones 3-4 and injection into zones 4-5 showing the highest increase.

Case AQUIFER gives the lowest cumulative production for all cases of waterflooding considered.

\section{Effects of ZoIP on the field oil production rate (FOPR)}

Figure 14 shows a plot of the oil-producing rate of the field versus time for a five-spot waterflood considering the three cases of ZoIP.

The plots show that the reservoir production is more effective when more zones of the reservoir can produce oil and inject water, with case ZONES 4-5 having the highest cumulative oil production for all periods after waterflooding. This is because production is largely a function of voidage. The more the zones injecting water, the higher the voidage replacement of reservoir fluids, and

\section{FOPT ZOIP}

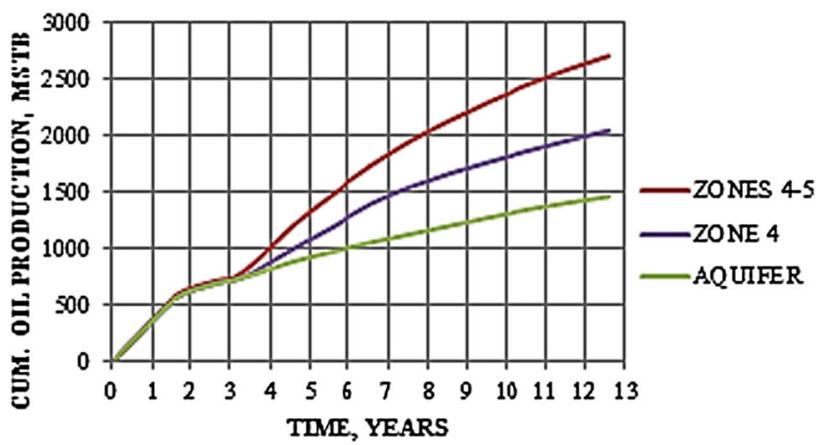

Fig. 13 Plot of field cumulative production versus time for the ZoIP scenarios for the five-spot waterflood

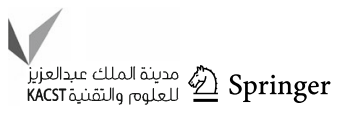




\section{FOPR_ZOIP}

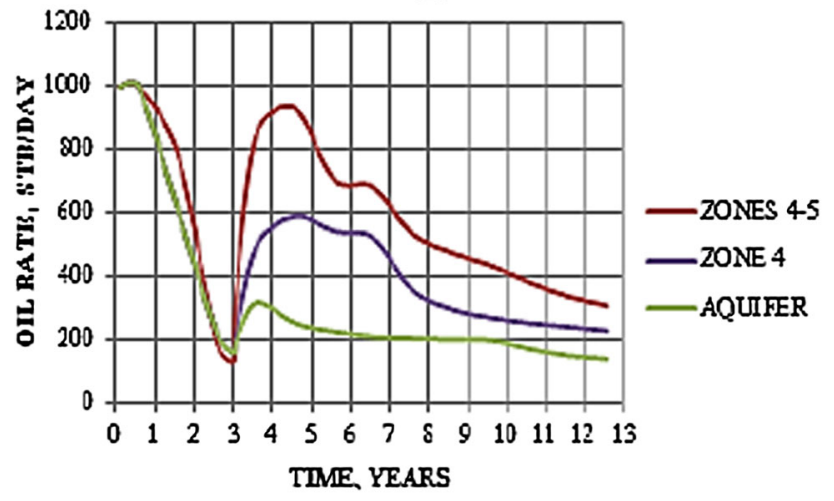

Fig. 14 Plot of field oil production rate versus time for different ZoIP scenarios for the five-spot waterflood

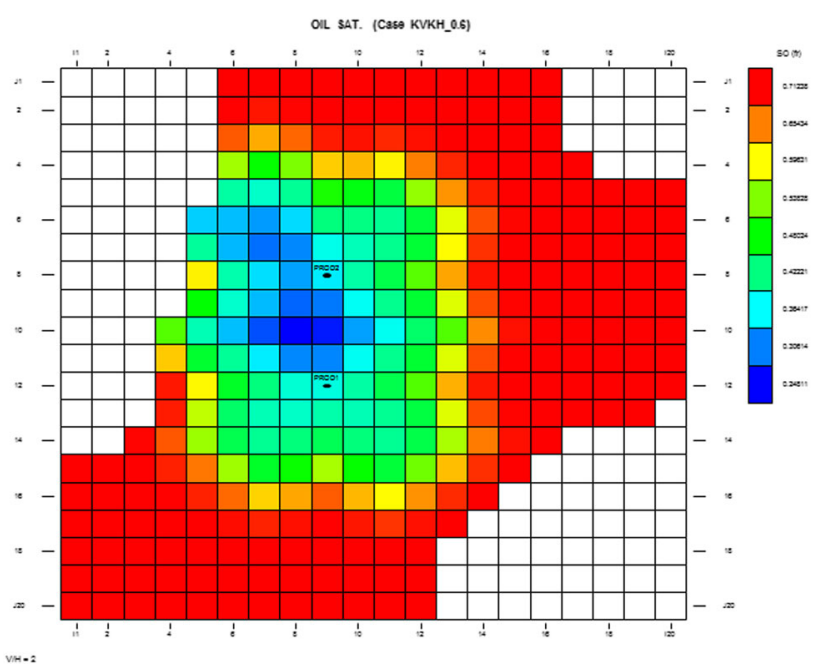

Fig. 15 2D Map showing the distribution of oil saturation across zone 3 of the reservoir X and the location of producers (PROD 1 and PROD 2) at the end of simulation (blank cells represent non-reservoir grid cells)

thus, a decline in production rate is curtailed. However, this is not good practice as it can also lead to very high water production.

Also, injection into zone 4 (ZONE 4) is seen to give higher production rates than the case of water injection into the aquifer (AQUIFER). This is because injection into oilbearing zones in the reservoir tends to displace more oil toward the producers than injection into the aquifer.

Figure 15 shows the distribution of oil saturation and the location of producers (PROD 1 and PROD 2) in the layer 3 of the reservoir after simulation.

\section{Effects of ZoIP on field water-cut (FWCT)}

Figure 16 shows a plot of field water-cut versus time of all the ZoIP cases.

\section{FWCT ZOIP}

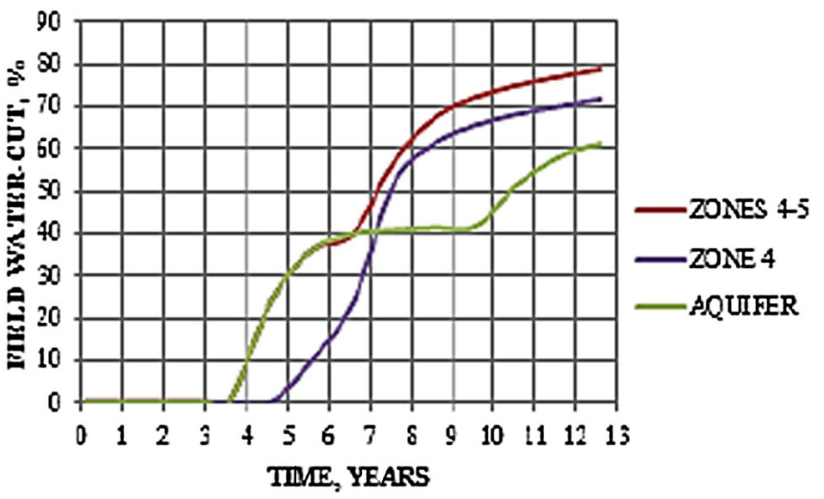

Fig. 16 Plot of field water-cut versus time for different ZoIP scenarios for the five-spot waterflood

It is observed that for all waterflood scenarios analyzed, none of the ZoIP cases considered had a significant amount of water production prior to waterflooding.

Also observed is that injecting water into fewer zones leads to a reduction in water production. Injection of water into more zones of the reservoir will lead to an increase in water production. It is seen that injection of water into zones other than the aquifer would result in high water-cut. This is because injection into such zones can cause a higher production of water with displaced oil.

Finally, water injection into the aquifer (case AQUIFER) is seen to have the least water production for all cases considered.

\section{Effects of ZoIP on field pressure (FPR)}

Figure 17 shows plots of field pressure versus time for the five-spot waterflood pattern. Observed from the figure is that pressure maintenance/increment is more effective when more zones of the reservoir can inject water with the scenario in which water was injected into two reservoir zones (ZONES 4-5) having the best pressure profile for all scenarios studied. This is because pressure decline is largely a function of voidage. If more zones in the reservoir are injecting water, there is voidage replacement, and thus, pressure decline is arrested.

Also, injection of water into zones 4 (case ZONE 4) is seen to give higher pressure increment than the case which involved injection into the aquifer. The injection into the aquifer (case AQUIFER) had no significant pressure maintenance effect as reservoir pressure is still observed to decline and injection into the aquifer only serves to maintain pressure and not necessarily boost it. This may be due to the presence of a small aquifer or an aquifer which is not in good communication with the reservoir. 


\section{FPR_ZOIP}

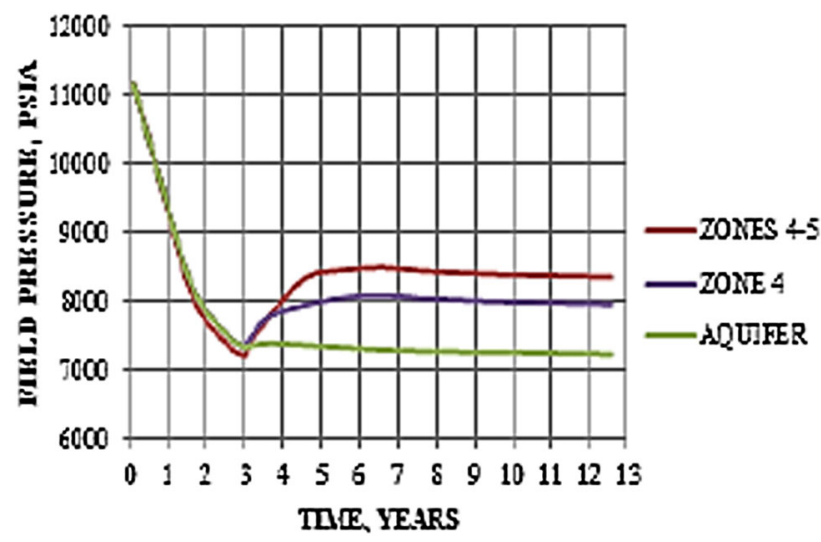

Fig. 17 Plot of field pressure versus time for different ZoIP scenarios for the five-spot waterflood

\section{Effects of waterflood patterns on the performance of the waterflood}

In this section, the impact of the selected waterflood patterns on waterflood performance is evaluated. This is carried out by analyzing trends in the field oil production rate, field water-cut, cumulative production and field reservoir pressure. The optimal pattern would be that pattern which would give the highest cumulative production with appreciable low water-cut.

\section{Field oil production rate (FOPR)}

Figure 18 shows a plot of oil production rate of the field versus time for the three patterns of waterflood considered-the five-spot, direct line drive and the staggered line drive waterfloods, respectively.

It is clearly observed from the figure that for all flood/ injection patterns evaluated, there were corresponding effects in the field oil production rate.

Also, cases LD (direct- line drive scenario) and SLD (staggered line drive) are observed to have higher oil production rates for periods after waterflooding. This is because the field was adequately furnished with producers which helped drain the reservoir and injectors which ensured that oil was sufficiently displaced toward these producers, hence maintaining the high oil rate observed. Also, the placement of the injectors in line with the producers allows for efficient displacement of oil by the advancing water front.

Finally, it is observed that the case 5_SPOT (a regular five-spot waterflood scenario) has the lowest oil rate of all the scenarios. This is due to the lack of sufficient producers which would adequately drain the reservoir. This is because the two producers (for the direct line drive and

\section{POWF_FOPR}

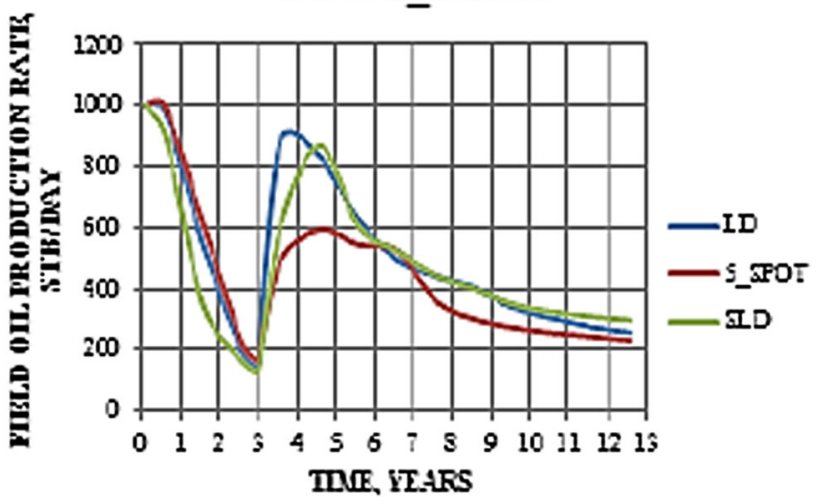

Fig. 18 Plot of the production rate of the field with time for different PoWF scenarios

staggered line drive patterns) have an advantage over one producer (for the 5-SPOT) as this implies that more zones of the reservoir are available for drainage by the producers.

\section{Effects of selected waterflood pattern on field water- cut (FWCT)}

Figure 19 shows a plot of water-cut of the field versus time for the three patterns of waterflood considered-the fivespot, direct line drive and the staggered line drive waterfloods, respectively.

It is observed that case LD (the direct -line drive pattern) and case SLD (the staggered line drive pattern) have similar water-cut trends which are higher than that of the five-spot waterflood pattern. This is due to the placement of the injectors in line with the producers in distance closer than those obtainable for the five-spot waterflood pattern and allows for the faster movement of the advancing water front toward the producers and hence higher water production and earlier water breakthrough.

\section{POWF_FWCT}

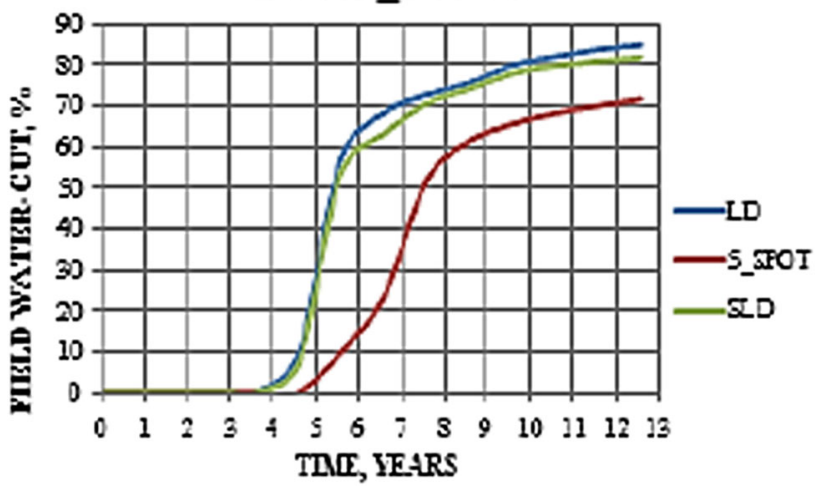

Fig. 19 Plot of field water-cut versus time for different PoWF scenarios 
Also, the five-spot waterflood scenario has the least water-cut throughout the period of simulation. This is because of the distance between the injectors and the producer in this case as compared with the other cases. This causes late water breakthrough and lower water production.

\section{Effects of selected waterflood patterns on the field cumulative production (FOPT)}

Figure 20 shows a plot showing the effect of the selected flood pattern on the cumulative oil production from the field.

It is observed that case LD (direct line drive pattern) gives the highest cumulative production for all scenarios analyzed. This is due to the efficient displacement of oil toward the producers by the injectors. In contrast, the case 5_SPOT (regular five-spot pattern) has a low cumulative production largely due to the absence of sufficient producers to produce displaced oil.

\section{Effects of selected waterflood pattern on field pressure (FPR)}

Figure 21 shows a plot of field pressure versus time for the scenarios of waterflood patterns considered - the five-spot, direct line drive and the staggered line drive waterfloods. From the figure, it is observed that the plots for the line drive patterns have higher pressure profiles than the fivespot patterns after waterflooding. This is largely due to the shorter distances between the injectors and the producers for these patterns as compared to the five-spot patterns.

Also, case SLD (the staggered line drive waterflood) shows the highest pressure increment after waterflooding for all patterns analyzed. This is because the lateral orientation of the injectors to the producers allows for

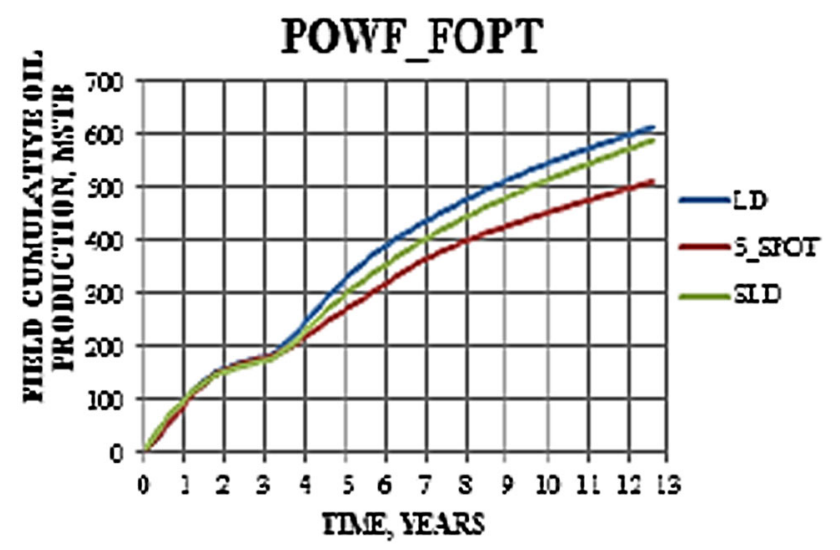

Fig. 20 Plot of field cumulative production versus time for different PoWF scenarios

\section{POWF_FPR}

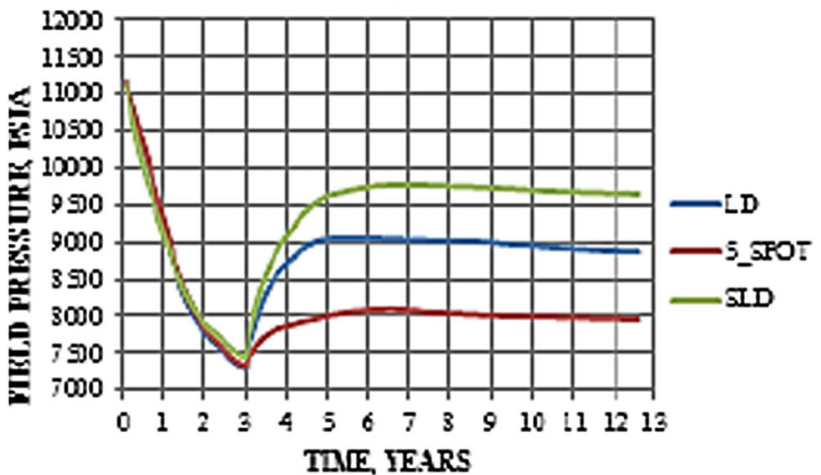

Fig. 21 Plot of average field pressure versus time for different PoWF scenarios

effective displacement of injected water and hence better pressure maintenance.

\section{Effect of number and type of wells on reservoir performance}

Under this section, the results of the optimum number of producers and injector required to adequately drain the reservoir will be discussed. Different scenarios involving the use of vertical and/or horizontal wells were simulated. The results are discussed in the following section using analysis of trends in field oil production rate, field watercut, cumulative production and field reservoir pressure. The optimum number of wells and type of well to be selected would be the scenario that gives the highest cumulative production and/or oil rate over time with a corresponding low water-cut.

\section{Effect of the number and type of wells on field oil production rate (FOPR)}

Figure 22 shows the plot for field oil rate versus time for all scenarios examined. Prior to waterflooding, it is observed that scenarios in which the producers are vertical (cases VI_VP and HI_VP) had rapidly declining flowrates as a result of the rapid depletion of oil-producing zones. Cases VI_HP and HI_HP (scenarios with horizontal producers) are also observed to have higher production rates compared to cases VI_VP and HI_VP. This is because for any given reservoir with good permeability anisotropy, horizontal wells have the ability to communicate with more zones in the reservoir than vertical wells and hence better oil recovery. However, a reversal of this trend is observed just month before waterflooding (between years 2.5 and 3) because of rapid reduction in oil production rates of the horizontal producers due to decline in initial reservoir energy. 
NToW_FOPR

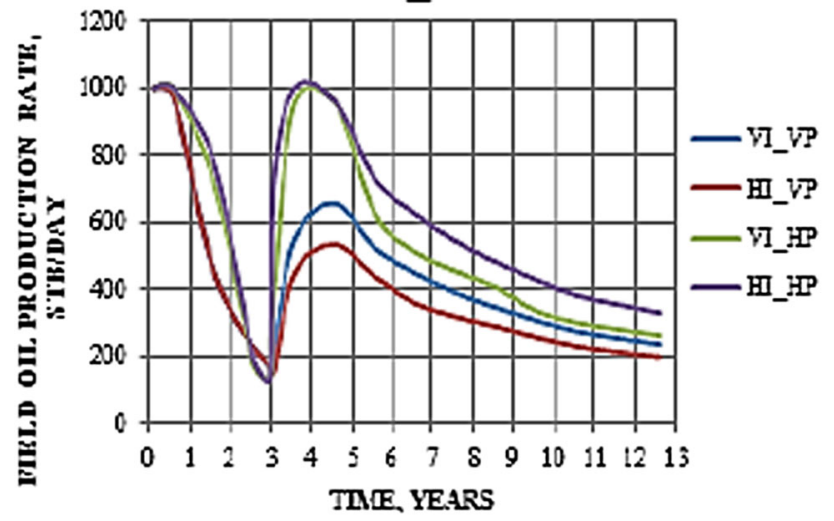

Fig. 22 Plot of the production rate of the field with time for different NToW scenarios

Upon waterflooding, it is observed that the scenarios with horizontal producers (HI_HP and VI_HP) have high field oil production rate compared to the other two scenarios in which production wells are vertical wells. The scenario in which both injectors and producers are horizontal (case HI_HP) is seen to have the highest oil production rate for all simulation periods after waterflooding. This is because water injection by the horizontal injector into the same zone for which oil is produced (zone 4) displaces oil more efficiently toward the producers than cases with vertical injectors which involved injection of water into zones 4 and 5. Cases with vertical producers, cases HI_VP and VI_VP are observed have the lowest production rate for all periods after waterflooding as these producers communicate with lesser zones of the reservoir.

Finally, case HI_VP is observed to give the lowest oil production rate. This is due to the inefficient displacement of oil by the advancing injected water as water is not injected into the same zones from with oil production is carried out. Also, recall that the production wells are in communication with lesser zones of the reservoir when compared to scenarios involving the use of horizontal wells.

\section{Effect of number and types of wells on field water- cut (FWCT)}

Figure 23 shows a plot of water-cut of the field versus time for the scenarios of number and type of producers/injectors considered. It is observed that for all scenarios, the reservoir had little or no water production before waterflooding. Upon waterflooding, water-cut for scenarios with vertical injectors, cases VI_VP and VI_HP are discovered to have the highest increase in water-cut. This is because in reservoirs with good vertical-to-lateral anisotropy, water
NToW_FWCT

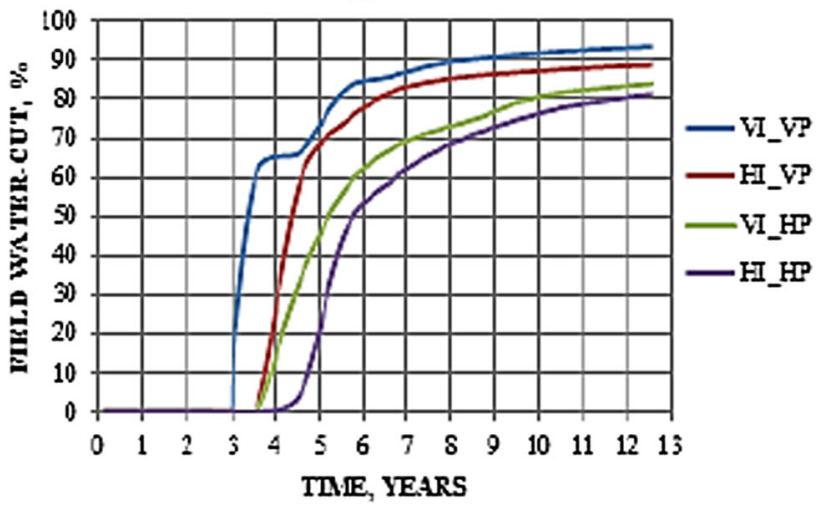

Fig. 23 Plot of the field water-cut with time for different NToW scenarios

will flow more conveniently in the upward vertical direction due to gravity rather than laterally and leads to higher water production at the producers.

Finally, case VI_VP gives the earliest water breakthrough time as water production is observed to begin upon waterflooding. This is because the completion of the producers close to the water-bearing zone of the reservoir creates higher tendency of early water coning.

\section{Effect of number and type of wells on field cumulative production (FOPT)}

Figure 24 shows a plot showing the effect of the selected number and type of producers and injectors on the cumulative oil production from the field. It is observed that scenario HI_HP has the highest cumulative production. This is because of horizontal producers which have the advantage of producing from more reservoir zones. This led to the steadily increasing oil recovery experienced.

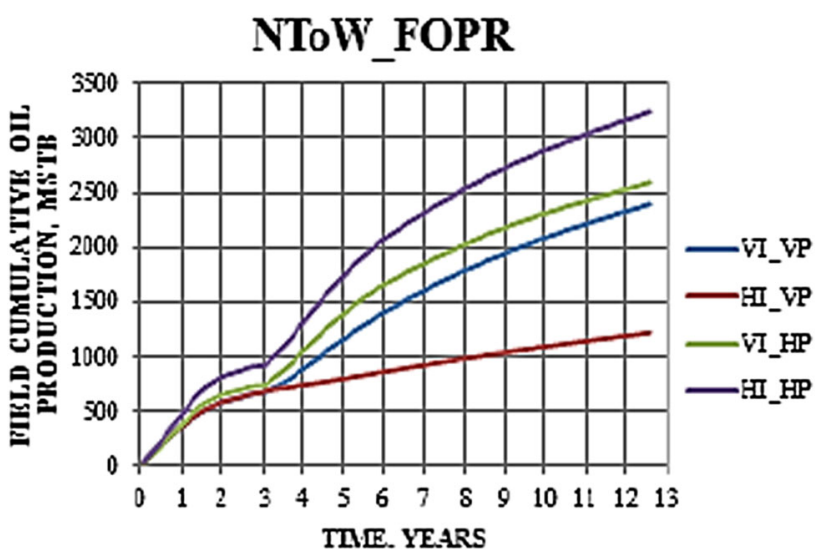

Fig. 24 Plot of the field cumulative oil production versus time for different NToW scenarios 


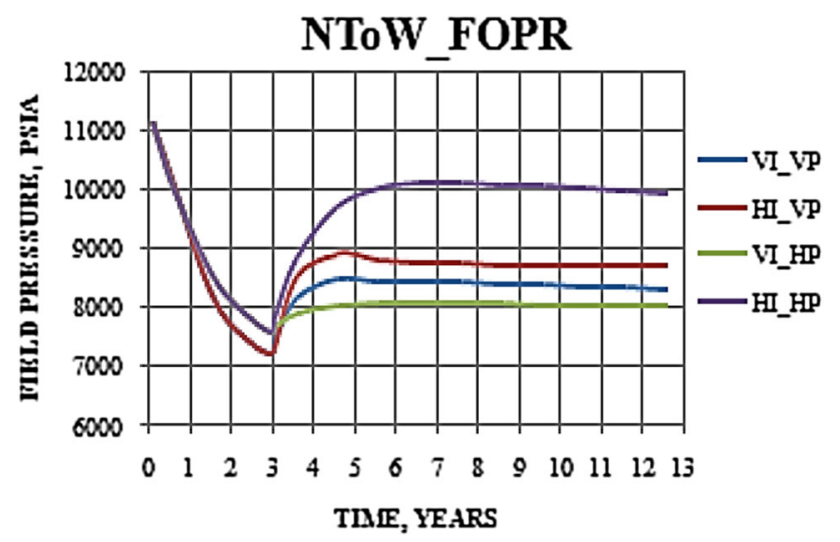

Fig. 25 Plot of the field pressure versus time for different NToW scenarios

Also since this scenario involves the use of horizontal injectors which are completed in the same zone as the producer, water flows to displace oil toward the producer more efficiently, and hence, more oil is drained at the producers.

Finally, cases with vertical producers, cases HI_VP and VI_VP are observed to have the lowest cumulative oil production throughout simulation as these producers communicate with lesser zones of the reservoir, and hence, oil production is lesser in these scenarios. Case HI_VP in which injectors are horizontal well and producers are vertical wells is observed to give the lowest cumulative oil production. The use of horizontal injectors and vertical producers is not good practice as there is inefficient displacement of oil by the advancing injected water because of well orientations. Also, the production wells in this scenario are in communication with lesser zones of the reservoir when compared to scenarios involving the use of horizontal producers.

\section{Effect of number and types of wells on average field pressure (FPR)}

Figure 25 shows a plot of the field pressure versus time for different scenarios of number and type of injectors and producers used. From the figure, it is observed that HI_HP had the highest pressure increment for the waterflood operation. This is because of the large number of zones into which water were injected. Pressure decline is largely a function of voidage, and when more reservoir zones can inject water, there is voidage replacement and pressure decline is arrested.

Also observed is that the average field pressure for the scenarios which involved the use of vertical injectors (VI_VP and VI_HP) showed the lowest pressure increment for all scenarios studied.

\section{Conclusions}

From the results obtained, it can be concluded that:

1. The geostatistical tool of co-simulation is a reliable and efficient tool for modeling and distributing reservoir petrophysical properties in a model.

2. Building of multiple equiprobable realizations of reservoir properties and ranking them are an efficient approach to reservoir characterization. This approach reduces uncertainties associated with reservoir properties estimation.

3. The combination of generating numerous equiprobable distributions of reservoir property and using numerical simulation to evaluate fluids distribution is an extremely useful approach for reservoir performance analysis.

4. Waterflood was optimized using an approach that considered the zones of injection and production, the pattern of waterflood and the number and type of producers/injectors.

Acknowledgements The authors would like to appreciate Mr. Brian Coates of Coat Engineering, Inc., USA, for donating the SENSOR 6K simulator software used for this research. Also acknowledged are Mr. Evans Boah Annah and Mr. Borsah Kofi Aidoo of African University of Science and Technology, Abuja, for the assistance they rendered.

Open Access This article is distributed under the terms of the Creative Commons Attribution 4.0 International License (http:// creativecommons.org/licenses/by/4.0/), which permits unrestricted use, distribution, and reproduction in any medium, provided you give appropriate credit to the original author(s) and the source, provide a link to the Creative Commons license, and indicate if changes were made.

\section{References}

Alhuthali AH, Oyerinde D, Datta-Gupta A (2006) Optimal waterflood management using rate control. Paper SPE 102478-PA-P presented at the 2006 SPE annual technical conference and exhibition, San Antonio, Texas

Asadollahi M (2012) Waterflooding optimization for improved reservoir management, Ph.D. dissertation, Norwegian University of Science and Technology (NTNU), Trondheim, Norway

Awejori GA (2010) Integrated petrophysical evaluation of turbiditic sands in Niger Delta Basin, M.Sc. Thesis, Unpublished, AUST, December

Bohling G (2005) Stochastics simulation and reservoir modeling workflow. C\&PE 940

Craft BC, Hawkins MF (1991) Applied petroleum reservoir engineering. Prentice Hall PTR, Englewood Cliffs

Craig FF (1971) The reservoir engineering aspects of waterflooding. Society of Petroleum Engineers, New York

Lach J (2010) IOR for deepwater Gulf of Mexico: phase 1, knowledge reservoir, Houston, Texas

Lake LW, Schmidt RL, Venuto PB (1992) A niche for enhanced oil recovery in the 1990s. Petroleum Engineer International 
Meshioye O, Mackay E, Chukuwezi M (2010) Optimization of waterflooding using smart well technology. Paper SPE 136996 presented at the 34th annual SPE international conference and exhibition held in Tinapa-Calabar, Nigeria

Nwaozo J (2006) Dynamic optimization of a water flood reservoir, M. Sc. Thesis, University of Oklahoma Graduate College, Norman, Oklahoma, USA

Ogali OI (2011) Waterflood optimization using streamline simulation. M.Sc., Thesis, Unpublished, AUST, Abuja

Remy N, Boucher A, Wu J (2009) Applied geostatistics with SGeMS. Cambrigde University Press, Cambridge
Spath J, McCants S (1997) Waterflood optimization using a combined geostatistical-3D streamline simulation approach: a field example. Paper 38355-MS presented at the SPE Rocky Mountain Regional Meeting, Wyoming

Thiele MR, Batycky RP (2006) Using streamline-derived injection efficiencies for improved waterflood management. Paper SPE 84080 presented at the 2006 SPE annual technical conference and exhibition, San Antonio, Texas

Tiab D, Donaldson EC (2004) Theory and Practice of measuring reservoir rock and fluid transport properties, 2nd edn. Gulf Professional Publishing, Burlington 